\title{
BENIGN CHONDROBLASTOMA OF BONE
}

\author{
Report of a Case
}

\author{
E. R. Treasure, Swansea, Wales \\ From the Orthopaedic Department, Llandough Hospital, Cardiff
}

Benign chondroblastoma occurs most commonly in the second decade, usually in boys. The upper end of the humerus, in the region of the epiphysis, is a favourite site. It is interesting for the following reasons: 1) it may be mistaken for a giant-cell tumour or sarcoma; 2 ) it is amenable to local surgery by curettage or excision; and 3) it has a uniformly good prognosis and seldom, if ever, becomes malignant.

The complaint is usually of pain or swelling. For this reason sarcoma is often suspected at first. Histologically, the tumour is composed of polyhedral cells, with a small amount of interstitial cell substance. The sections show focal areas of calcification, and where cells and ground substance have become encrusted with calcium the tissue is necrotic. In some areas there may be direct metaplasia into bone.

The tumour was first described by Codman in 1931 as " epiphysial chondromatous giantcell tumour of the upper end of the humerus." Codman believed that the peculiar structure of the upper end of the humerus modified the picture of a giant-cell tumour so that it did not often occur in typical form. The nature of the tumour was not clearly established until Jaffe and Lichtenstein reported several cases in 1942, with a follow-up of up to twelve years. They called the tumour benign chondroblastoma. They found that it was not confined to the head of the humerus but occurred at other sites such as the tibia, femur or ilium. Both Codman and Jaffe were of the opinion that the tumour was epiphysial in origin.

Diagnosis-Provided clinical data are combined with histological findings, the diagnosis should not be difficult, but giant-cell tumour and sarcoma, including Ewing's sarcoma, must be borne in mind.

\section{CASE REPORT}

The patient was a boy aged fourteen years. He complained of "giving way" of the left arm on lifting heavy weights, and of aching pain in the left shoulder, sufficient to keep him awake at night. These symptoms had been noticed for a year. On examination, his general condition was good. There was some wasting around the left shoulder, and there was a localised point of tenderness three inches below and behind the acromion. Muscle power was weak but the range of shoulder movements was full. There was no evidence of a neurological disturbance. Radiographs showed an oval translucency in the medial part of the humeral epiphysis involving the metaphysis, with some distortion of the bone outline (Fig. 1).

Findings at operation-Under general anaesthesia the head of the humerus was approached from the front. There was some difficulty in defining the muscle planes because of periarticular fibrosis. Inspection of the head of the humerus showed a roughened area of abnormal bone extending from below the medial articular margin and involving about a quarter of the articular surface. The tumour was soft and pale grey in colour. There was no cystic space. The area was curetted down to firm bone. The cavity was left.

Histological examination - The microscopic appearances were characteristic of chondroblastoma (Fig. 3). In one of the photomicrographs typical calcified areas were seen.

Progress-The patient was treated in a collar-and-cuff sling. Early movement was encouraged. When the patient was re-examined two years after the operation he was free from symptoms and had a full range of shoulder movement under good muscle control. 


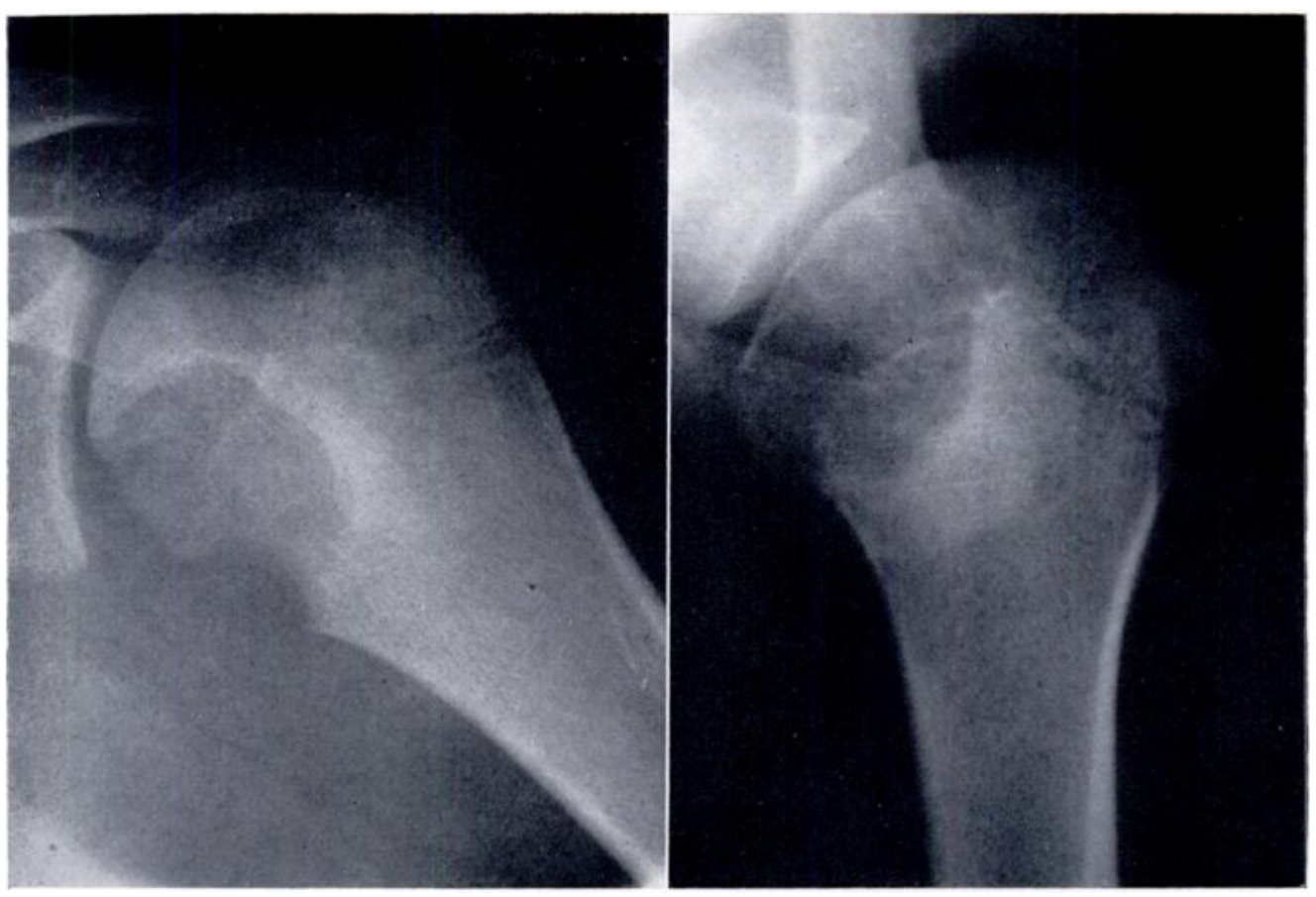

FIG. 1

Radiograph before operation.

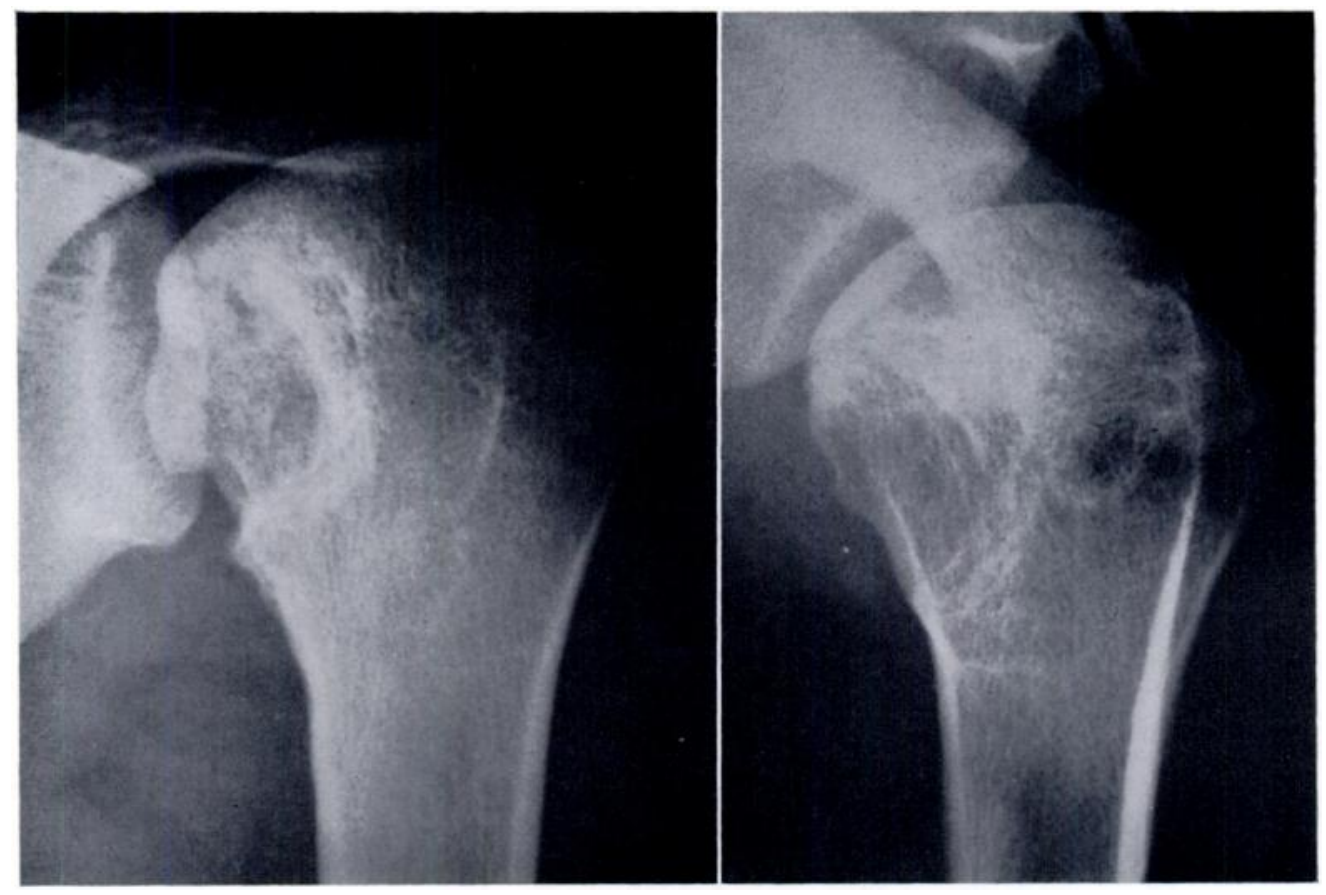

Fig. 2

condition two years after curettage.

Vol. 37 B, No. 3, A०Gist 1955 


\section{DISCUSSION}

The methods that have been used in the treatment of chondroblastoma of bone include irradiation, curettage, and local excision of the tumour with marginal bone. I believe that surgery is the treatment of choice and that x-ray therapy should probably never be used. Most authors who have described this condition have favoured surgery.

With regard to $x$-ray therapy, the remarks of Cade (1949) on the treatment of giant-cell tumour of bone have an important bearing on the treatment of chondroblastoma: "In the search for truth certain fundamental principles become clear . . Tumours in children should seldom be irradiated because the treatment may cause epiphysial injury and deformity. Case reports in the literature with a follow-up of not more than three to five years cannot be relied

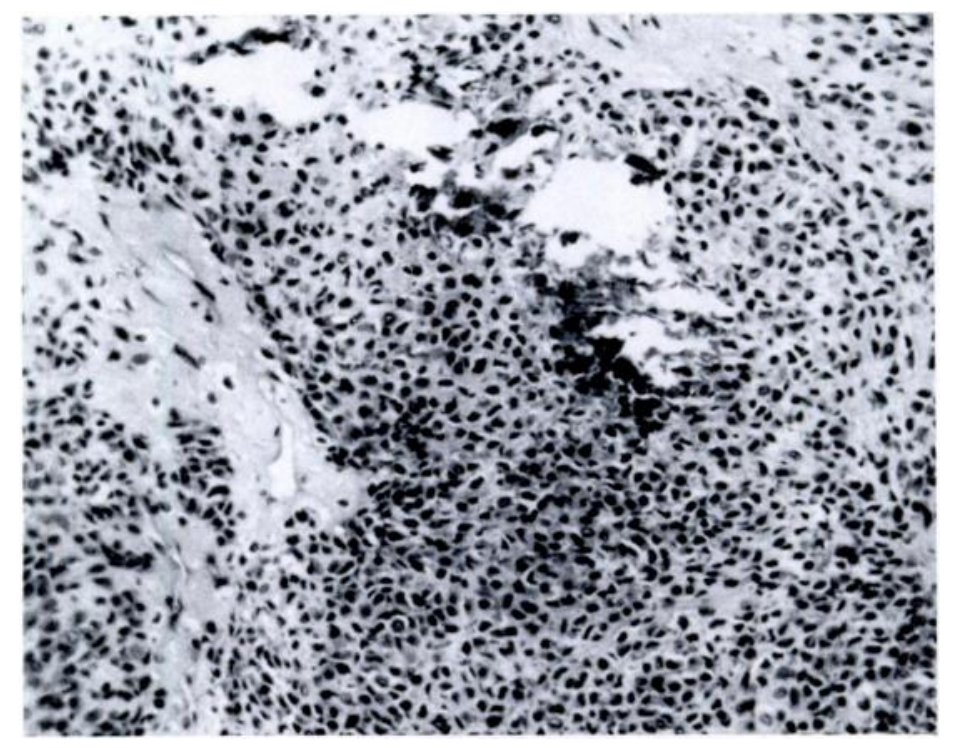

Fig. 3

Photomicrograph from a section of the tumour. $(\because 170$.

upon. The long-term effects of irradiation in children, with irreversible damage that may be disastrous, cannot be judged in less than ten to fifteen years." He also stated that bone sarcoma could be induced by irradiation and quoted eleven cases in which a benign tumour treated by irradiation, with or without surgical intervention, became malignant. Many cases of osteogenic sarcoma have developed in irradiated bone up to twenty-two years after the initial exposure although in many cases the dosage was greater than the 2,000 Roentgen now in use.

In view of the risks of irradiation and the unanimous report of many observers that surgery is effective in this tumour I believe that the case against radiotherapy is proved.

Incidence of the tumour-Benign chondroblastoma may be more common than is now believed. For instance, it is notable that of twenty-five cases of giant-cell tumour described by Prossor (1949) six occurred in patients under the age of seventeen years. In three instances biopsy was performed and in each a diagnosis of benign giant-cell tumour was made. In the remaining three cases biopsy does not appear to have been done; in all three the tumour was in the upper end of the humerus, but it was not recorded whether the tumours were primarily metaphysial or epiphysial. Treatment in these cases was by $\mathrm{x}$-ray therapy of a dosage within or about the limit of 2,000 Roentgen. The reported results were satisfactory. It is reasonable to suppose that had these tumours been submitted to biopsy, one or more might have been a chondroblastoma. 
The importance of biopsy-I submit that biopsy should be performed in every case. Without biopsy the diagnosis must always be speculative, and biopsy is essential for scientific classification of the tumours in a Bone Registry, if available. There is no evidence that biopsy has done harm and, moreover, excision biopsy may combine therapy and diagnosis effectively.

\section{SUMMARY}

A case of benign chondroblastoma in the upper end of the humerus is described. A plea is made that radiotherapy should be avoided in the treatment of this tumour. It is suggested that biopsy should be performed in every case.

MY thanks are due to Mr Dillwin Evans for permission to publish this case and for advice, and to Mr E. Mervyn Evans, Professor J. Gough, and Dr Roger Seal. I am grateful also to Dr H. L. Jaffe, who kindly examined the microscopic sections, and to $\mathrm{Mr} \mathrm{W}$. T. Gower for the $\mathrm{x}$-ray photographs.

\section{REFERENCES}

CADE, S. (1949): Giant-cell Tumour of Bone. Journal of Bone and Joint Surgery, 31-B, 158.

Codman, E. A. (1931): Epiphyseal Chondromatous Giant Cell Tumors of the Upper End of the Humerus. Surgery, Gynecology and Obstetrics, 52, 543.

Jaffe, H. L., and Lichtenstein, L. (1942): Benign Chondroblastoma of Bone: a Reinterpretation of the So-called Calcifying or Chondromatous Giant Cell Tumor. American Journal of Pathology, 18, 969.

Prossor, T. M. (1949): Treatment of Giant-cell Tumours of Bone with a Review of Twenty-five Cases. Journal of Bone and Joint Surgery, 31-B, 241. 